\title{
COMPARISON OF STATISTICALLY CONTROLLED RAPID CASTING SOLUTIONS OF ZINC ALLOYS USING THREE DIMENSIONAL PRINTING
}

\author{
R. Singh \\ ${ }^{1}$ Faculty of Production Engineering, Guru Nanak Dev Engg. College \\ Ludhiana-141006, India \\ Phone: +91 98722 57575, Fax: +91 1612502700 \\ E-mail: rupindersingh78@yahoo.com
}

\begin{abstract}
In the present work, the most cost effective/best shell wall thickness of mould cavities has been compared with other available shell wall thicknesses for statistically controlled rapid casting solutions of zinc alloy. Starting from the identification of component/ benchmark, technological prototypes were produced at different shell thicknesses with three dimensional printing. The results of the study suggest that at the best shell wall thickness $(7 \mathrm{~mm})$ for zinc alloys, the rapid casting solution is statistically controlled, which is not observed for all shell wall thicknesses of mould cavities prepared with three dimensional printing.
\end{abstract}

Keywords: Three dimensional printing, statistically controlled rapid casting, zinc alloys, dimensional accuracy, rapid casting.

\section{INTRODUCTION}

Three dimensional printing (3DP) is a relatively new form of Rapid Prototyping (RP). The 3DP process was patented by Sachs et al. (1994) under US Patent Number 005340656. It was developed at Massachusetts Institute of Technology (MIT) and licensed to Soligen Corporation, Extrude Hone and Z Corporation of Burlington (Singh and Verma, 2008). Techniques based on layer-by-layer manufacturing are extending their fields of application, from building of aesthetic and functional prototypes to the production of tools and moulds for technological prototypes (Karapatis et al., 1998). In particular, additive construction applied to the production of dies and electrodes, directly from digital data, is defined as rapid tooling (RT). Patterns, cores and cavities for metal castings can be obtained through rapid casting (RC) techniques (Singh and Singh, 2009a). In both cases, since the tooling phase is highly time-consuming, great competitive advantages can be achieved (Singh, 2008a). Moreover, RT and RC processes allow the simultaneous development and validation of the product and of the manufacturing process. Technological prototypes can constitute a strategic means, not only for functional and assembly tests or to obtain the customer's acceptance, but mainly to outline eventual critical points in the production process (Singh and Singh, 2008). The relevance of RC techniques consists, above all, in a short time for parts availability (Bassoli et al., 2006). Traditionally, in order to produce cast prototypes a model and eventual cores have to be created, involving time and costs that hardly match the rules of the competitive market. For this reason, functional tests are typically performed on prototypes obtained by metal cutting, which are not effective in outlining issues related to the manufacturing process. The possibility to verify the usefulness of a 
technological solution, in the early stages of the product development, ensures a 'concurrent engineering' approach and minimizes the risk of late modifications of the definitive production tools (Bernard et al., 2003). The initial cost increase can thus be repaid through a reduction of costs and time for the following phases of development, engineering and production, as well as through non-monetary advantages (Wang et al., 1999). In particular, for relatively small and complex parts, the benefits of additive construction can be significant (Dimitrov et al., 2006). In this field, innovative solutions are now available based on the 3DP process, which can extend $\mathrm{RC}$ possibilities thanks to the lower costs with respect to previous technologies such as laminated object manufacturing of sand casting. One such technological solution in shell casting is starting from starch patterns produced on 3DP conceptual modelers (Radstok, 1999). A second solution is 3DP technology with the use of a ceramic material that allows the production of complex cavities and cores, suitable for casting light alloys (Dimitrov et al., 2007). A key issue regarding the shell casting process is the production of the pattern in the case of a prototype casting, for which traditional die casting is uneconomical. Rapid prototyping techniques can meet this requirement, producing single/few parts in short times and without tooling costs (Verma, 2008; Singh and Singh, 2009b). The present research regards shell patterns obtained by 3DP on which the ceramic shell can be built and then joined (as in the conventional process) to obtain the cavity for pouring metal. Experimental studies regarding this solution are lacking in literature, and in particular the technological feasibility in the case of thin-walled parts needs to be assessed (Singh, 2010).

In the current work, the 3DP technology has been used as rapid shell casting to make the shell moulds for zinc alloy. An effort has been made through experiments to study the feasibility of decreasing the shell wall thickness from the recommended one $(12 \mathrm{~mm})$, in order to reduce the cost and time of production as well as to evaluate the dimensional accuracy and mechanical properties of the zinc alloy castings obtained, for assembly purposes. The following objectives have been set for the present experimental study:

a) To study the feasibility of decreasing the shell thickness from the recommended $12 \mathrm{~mm}$ for statistically controlled rapid casting solution of zinc alloy in order to reduce the production cost and time.

b) Comparison of cost effective/best shell wall thickness of the mould cavity with other available shell wall thicknesses for statistically controlled rapid casting solutions of zinc alloy.

c) To evaluate the dimensional accuracy of the castings obtained and to check the consistency of the tolerance grades of the castings (IT grades) as per the IS standards for the casting process.

\section{EXPERIMENTATION}

In order to accomplish the above objectives, 'zinc alloy casting' has been chosen as the benchmark. The component selected for the present study is shown in Figure 1 (Singh and Singh, 2008). 

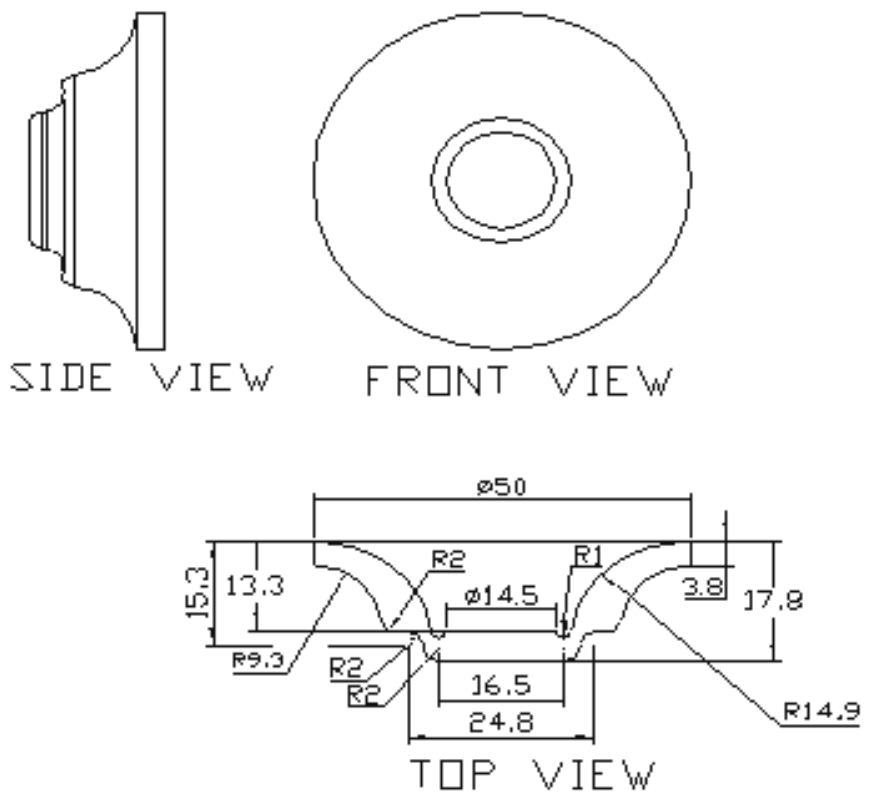

Figure 1. Benchmark dimensions (Singh and Singh, 2008)

The experimental procedure started with drafting/ model creation using AutoCAD software (Figure 2).

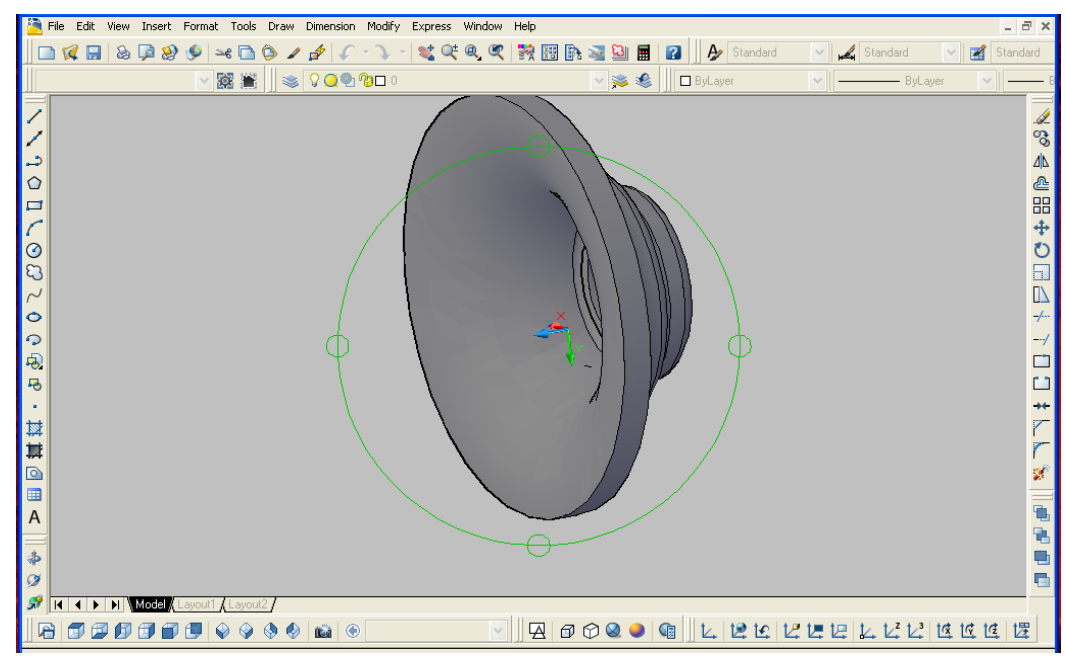

Figure 2. CAD model of the casing chosen as a benchmark (Singh and Singh, 2008) planned:

For the rapid casting process based on 3DP, the following phases have been

1. After the selection of the benchmark, the component to be built was modelled using a CAD. The CAD software used for the modelling was UNIGRAPHICS Ver. NX 5.

2. The upper and lower shells of the split pattern were made for different values of the thickness. The thicknesses of the shells were 12, 11, 10, 9, 8, 7, 6, 5, 4, 3, 2 and $1 \mathrm{~mm}$. 
3. The CAD models of the upper and lower shells were converted into STL (standard triangulation language) format, also known as stereo lithography format (Figure 3).

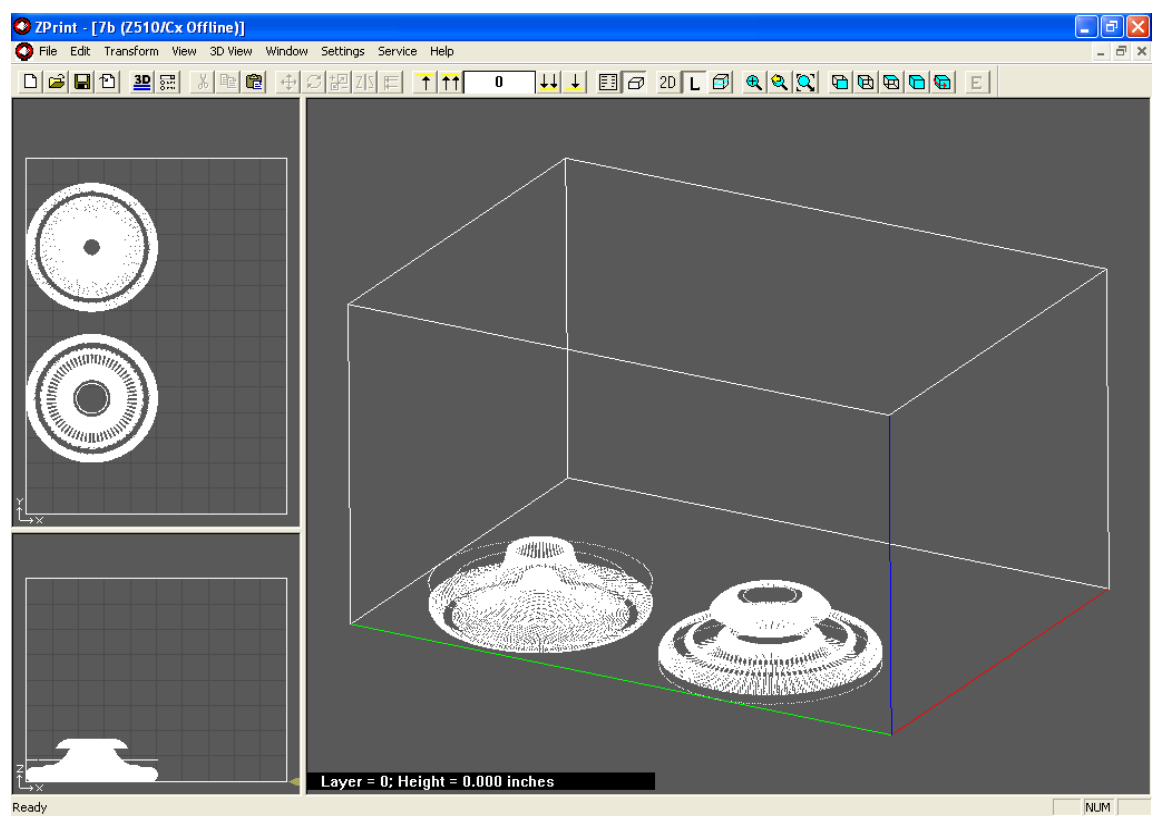

Figure 3. Triangular facets of the shells

4. Moulds were manufactured in 3DP (Z Print machine, Model Z 510) with Z Cast 501 powder, and parts were heat-treated at a temperature of $110^{\circ} \mathrm{C}$ for 1 hour. The upper and lower shells were placed in such a way that the central axes of the two shells were co-linear. The co-linearity of the shells was checked with the help of a surface profilometer, and zinc alloy was poured for obtaining the technological prototype (Figures 4 and 5).
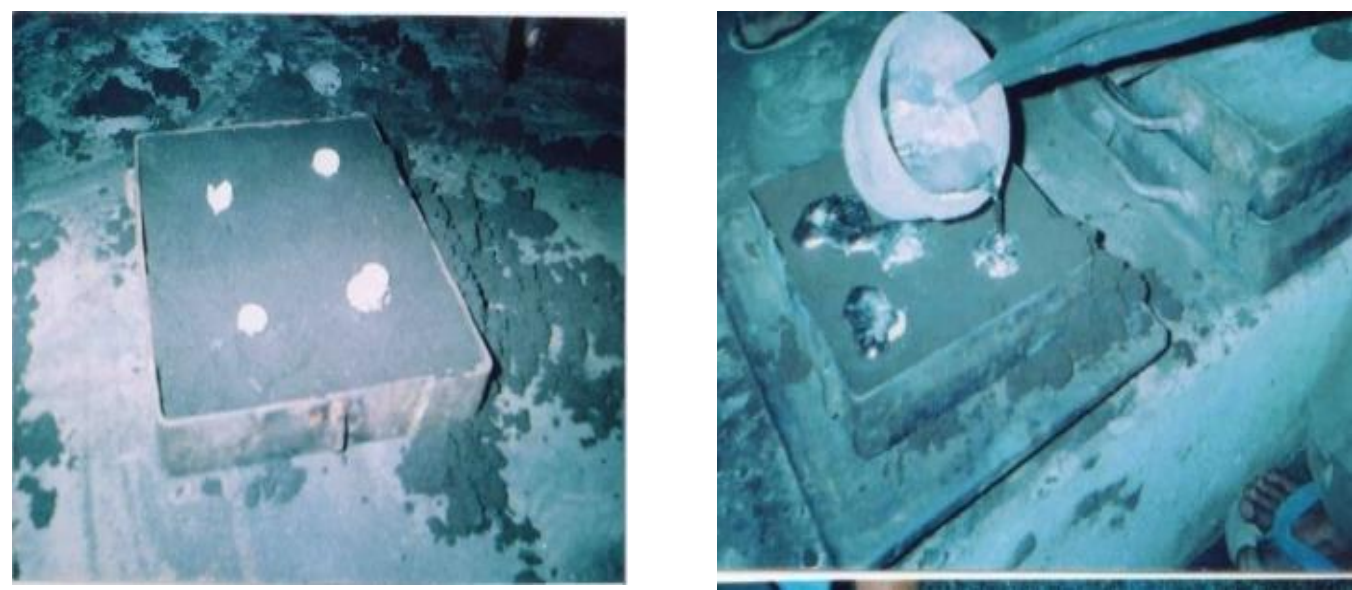

Figure 4. Technological prototype prepared by 3DP 


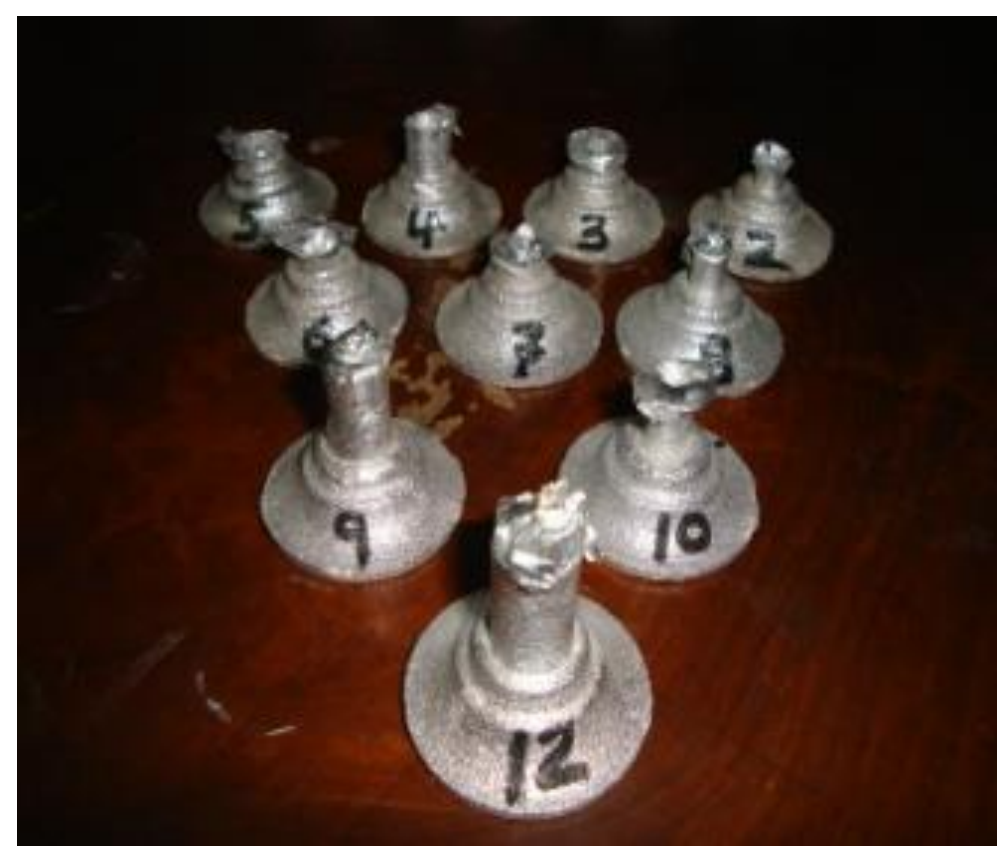

Figure 5. Zinc alloy casting solutions at different shell thickness

The measurement paths for the internal and the external surfaces of the benchmark were generated through the measurement software of the GEOPAK v2.4.R10 CMM. These paths direct the movements of the CMM probe along trajectories normal to the part's surface. About 70 points were measured on the external surface. For each point the machine software evaluates the deviations between the measured positions and the theoretical ones for the $X, Y, Z$ coordinates. Table 1 lists variations in the measured dimension of the outer diameter and the hardness of the castings prepared with respect to shell thickness (mm).

Table 1. Observations of final experimentation for zinc alloy casting

\begin{tabular}{cccc}
\hline Sl. NO & $\begin{array}{c}\text { Shell mould } \\
\text { thickness }\end{array}$ & $\begin{array}{c}\text { Avg. diameter } \\
(\mathbf{m m})\end{array}$ & $\begin{array}{c}\text { Hardness } \\
(\text { VHN })\end{array}$ \\
\hline 1 & 12 & 49.386 & 47 \\
2 & 10 & 48.954 & 54 \\
3 & 9 & 48.665 & 45 \\
4 & 8 & 49.265 & 48 \\
5 & 7 & 49.414 & 47 \\
6 & 6 & 49.529 & 50 \\
7 & 5 & 48.812 & 50 \\
8 & 4 & 48.453 & 56 \\
9 & 3 & 48.816 & 50 \\
10 & 2 & 48.890 & 47 \\
11 & 1 & Broken under metal pressure \\
\hline
\end{tabular}

It should be noted that in casting neither higher nor lower hardness is desirable (Kaplas and Singh, 2008). This is because if casting is too hard, it is usually brittle and if not hard enough it will be of a ductile nature. In the present experimental study the variation in hardness is not great. The only reason to measure and compare the hardness 
value is to show that for the optimum size shell thickness prepared by 3DP, the castings produced have little variation in hardness. So there will not be any problem in its functional operations. The results of the dimensional measurements were used to evaluate the tolerance unit $(n)$ that derives from the standard tolerance factor $i$, as defined in standard UNI EN 20286-1 (1995). The values of standard tolerances corresponding to IT5-IT18 grades, for nominal sizes up to $500 \mathrm{~mm}$, were evaluated considering the standard tolerance factor $i(\mu \mathrm{m})$ indicated by the following formula, where $D$ is the geometric mean of the range of nominal sizes in mm (Kaplas and Singh, 2008).

$$
i=0.45 D^{\frac{1}{3}}+0.001 D
$$

In fact, the standard tolerances are not evaluated separately for each nominal size, but for a range of nominal sizes. For a generic nominal dimension $D_{J N}$, the value of the tolerance unit's $n$ is evaluated as follows:

$$
n=1000\left(D_{J N}-D_{J M}\right) / i
$$

where $D_{J M}$ is measured dimension.

The tolerance is expressed as a multiple of $i$ : for example, IT14 corresponds to $400 i$ with $n=400$. Table 2 shows classification of different IT grades according to UNI EN 20286-1. After this, for each value of the outer diameter, the corresponding value of ' $n$ ' was calculated, the latter taken as a reference index for evaluation of the tolerance grade.

\begin{tabular}{|c|c|c|c|c|c|c|}
\hline \multirow{2}{*}{$\begin{array}{l}\text { Exp. } \\
\text { No. }\end{array}$} & \multirow{2}{*}{$\begin{array}{c}\text { Shell } \\
\text { thickness } \\
(\mathbf{m m})\end{array}$} & \multicolumn{2}{|c|}{$\begin{array}{c}\text { Outer Diameter } \\
(\mathbf{m m})\end{array}$} & \multirow{2}{*}{$\begin{array}{l}\text { Standard } \\
\text { Tolerance } \\
\text { Factor (i) }\end{array}$} & \multirow{2}{*}{$\begin{array}{c}\text { Tolerance } \\
\text { unit (n) }\end{array}$} & \multirow{2}{*}{$\begin{array}{c}\text { IT } \\
\text { Grades }\end{array}$} \\
\hline & & $\mathbf{D}_{\mathrm{JN}}$ & $\mathbf{D}_{\mathrm{JM}}$ & & & \\
\hline 1 & 12 & 50 & 49.386 & 1.58 & 389 & IT13 \\
\hline 2 & 10 & 50 & 48.954 & 1.58 & 662 & IT15 \\
\hline 3 & 9 & 50 & 48.665 & 1.58 & 845 & IT15 \\
\hline 4 & 8 & 50 & 49.265 & 1.58 & 465 & IT14 \\
\hline 5 & 7 & 50 & 49.414 & 1.58 & 371 & IT13 \\
\hline 6 & 6 & 50 & 49.529 & 1.58 & 298 & IT13 \\
\hline 7 & 5 & 50 & 48.812 & 1.58 & 752 & IT15 \\
\hline 8 & 4 & 50 & 48.453 & 1.58 & 979 & IT15 \\
\hline 9 & 3 & 50 & 48.816 & 1.58 & 749 & IT15 \\
\hline 10 & 2 & 50 & 48.89 & 1.58 & 703 & IT15 \\
\hline
\end{tabular}

Table 2. Class of different IT grades according to UNI EN 20286-1(1995)

Further (based upon observations of Table 1), to understand whether the process is statistically controlled, six samples of zinc alloy pieces were cast for the best shell thickness value of $7 \mathrm{~mm}$. On measurement of the outer diameter with CMM, the dimensions obtained are shown in Table 3. Based upon observations in Table 3, a runchart of the measured values of the outer diameter was developed (Figure 6). 
Table 3. Benchmark dimensional value at $7 \mathrm{~mm}$ shell wall thickness

\begin{tabular}{ccccc}
\hline SI NO & Observation & Mean & Above or Below Mean & Up or Down \\
\hline 1 & 49.403 & 49.41567 & $\mathrm{~B}$ & \\
2 & 49.401 & 49.41567 & $\mathrm{~B}$ & $\mathrm{D}$ \\
3 & 49.411 & 49.41567 & $\mathrm{~B}$ & $\mathrm{U}$ \\
4 & 49.415 & 49.41567 & $\mathrm{~B}$ & $\mathrm{U}$ \\
5 & 49.429 & 49.41567 & $\mathrm{~A}$ & $\mathrm{U}$ \\
6 & 49.435 & 49.41567 & $\mathrm{~A}$ & $\mathrm{U}$ \\
MEAN & 49.41567 & & $\mathrm{E}_{\mathrm{AB}=1}$ & $\mathrm{E}_{\mathrm{UD}=1}$ \\
\hline
\end{tabular}

$\mathrm{A}=$ above the mean, $\mathrm{B}=$ below the mean, $\mathrm{U}=$ up from previous reading, $\mathrm{D}=$ down from previous reading

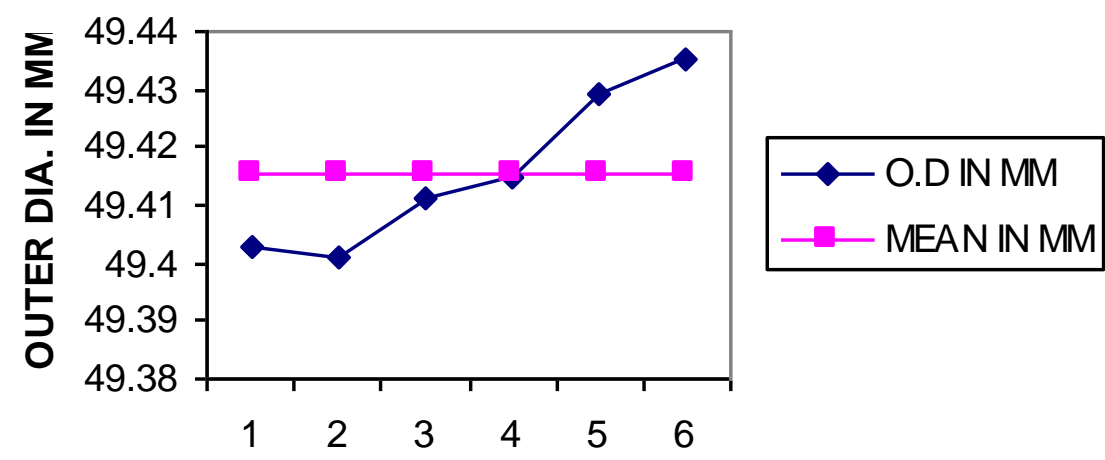

NO. OF OBSERV ATIONS

Figure 6. Run-chart of measured values of benchmark diameter (for $7 \mathrm{~mm}$ shell wall thickness)

Now if the mean and standard of a population that has a normal distribution are $\mu$ and $\sigma$ respectively, then for variable data $X$ the standard normal deviate $Z$ is defined as

$$
Z=\frac{\left(X_{i}-\mu\right)}{\sigma}
$$

where $X_{i}$ is the variable data obtained, $\mu$ is the mean of data and $\sigma$ is the standard deviation (Devor et al., 2005).

Calculation for $Z$ (standard normal deviate) above and below (for $7 \mathrm{~mm}$ shell wall thickness):

$$
E(\text { run })_{A B}=\left(\frac{N}{2}+1\right)
$$

where $N$ is the number of observations and $E$ (run) $)_{\mathrm{AB}}$ is the expected number of runs above and below.

$$
E(\text { run })_{A B}=\left(\frac{6}{2}+1\right)=4
$$




$$
\sigma_{A B}=\sqrt{\left(N-\frac{1}{4}\right)}
$$

where $\sigma_{A B}$ is the standard deviation of above and below.

$$
\begin{gathered}
\sigma_{A B}=\sqrt{\left(6-\frac{1}{4}\right)}=1.118 \\
Z_{A B}=\left[R U N_{A B}-E(\text { run })_{A B}\right] / \sigma_{A B}
\end{gathered}
$$

where $R U N_{A B}$ is the actual number of runs obtained above and below.

$$
Z_{A B}=[1-4] / 1.118=-2.6834
$$

$P=\operatorname{NORMSINV}(Z)$ when the value of $Z$ is negative (using Microsoft Excel software)

$$
P=0.003645
$$

For up and down calculations,

$$
E(\text { run })_{U D}=\left(2 N-\frac{1}{3}\right)
$$

where $N$ is the number of observations and $E$ (run) $)_{\mathrm{UD}}$ is the expected number of runs up and down.

$$
\begin{aligned}
E(\text { run })_{U D} & =\left(2 \times 6-\frac{1}{3}\right)=3.667 \\
\sigma_{U D} & =\sqrt{\left(16 N-\frac{29}{90}\right)}
\end{aligned}
$$

where $\sigma_{U D}$ is the standard deviation for up and down.

$$
\begin{gathered}
\sigma_{U D}=\sqrt{\left(16 \times 6-\frac{29}{90}\right)} \\
\sigma_{U D}=0.8628 \\
Z_{U D}=\left[R U N_{U D}-E(\text { run })_{U D}\right] / \sigma_{U D} \\
Z_{U D}=[1-3.667] / 0.8628 \\
Z_{U D}=-3.091
\end{gathered}
$$

$P=\operatorname{NORMSINV}(Z)$ when the value of $Z$ is negative (using Microsoft Formula)

$$
P=0.000997
$$


Normally decision making is done with a certain margin of error ' $\alpha$ ' and taken as equal to 0.005 , indicating that there is a $5 \%$ chance of arriving at the wrong conclusion.

\section{Decision Making}

If $P_{A B}<\alpha$ OR / \& $P_{U D}<\alpha$ then a non-random pattern exists.

In the present case $P_{A B} \& P_{U D}$ are $<\alpha$, indicating the existence of a non-random pattern.

Now the exercise of predicting various statistical or drawing conclusions should not be undertaken unless the normality of the distribution has been verified. Even if one has a large quantity of data, superimposing a normal curve on the histogram is a more difficult task than might be imagined. For a histogram, one requires a minimum of 50 observations, but more is better, and assessing whether the underlying distribution is normal or not becomes more difficult when the number of observations is fewer. For the cumulative probability plot $\left(P_{i}\right)$

$$
P_{i}=\frac{(S . N-0.5)}{N}
$$

where $S . N$ is the serial number of the data observation arranged in ascending order, and $N$ is the total number of observations in the data set. If the standard normal deviate follows normal distribution that has mean $\mu=0$ and standard deviation $\sigma=1$, then

$$
f(Z)=1 / \sqrt{2 \pi e^{\frac{z^{2}}{2}}}
$$

The equation above follows a normal probability curve and any data close to it also follow a normal probability curve. The values of standard normal deviate were calculated using cumulative probability, and dimensional values were arranged in ascending order, as shown in Table 4 . Based on Table 4, a normal probability curve was drawn to predict the probability, as shown in Figure 7.

Table 4. Standard normal deviate and outer diameter in ascending order

\begin{tabular}{cccc}
\hline S.NO & Pi (Cumulative Probability) & Std. Nor. Deviate Z & Dimensional value in mm \\
\hline 1 & 0.08333 & -1.38299 & 49.401 \\
2 & 0.25 & -0.67449 & 49.403 \\
3 & 0.416667 & -0.21043 & 49.411 \\
4 & 0.58333 & 0.21043 & 49.415 \\
5 & 0.75 & 0.67449 & 49.429 \\
6 & 0.91667 & 1.382994 & 49.435 \\
\hline
\end{tabular}




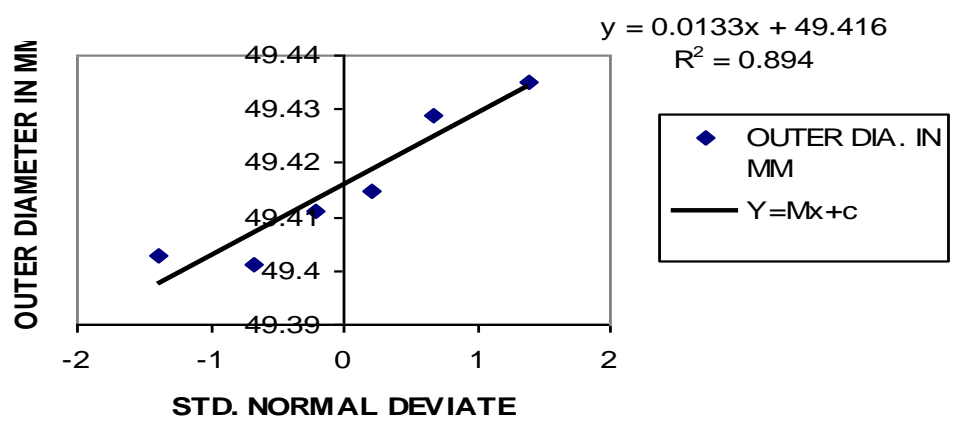

Figure 7. Normal probability curve (for selected benchmark at $7 \mathrm{~mm}$ shell thickness)

As observed in Figure 7, the aforesaid data follow a non-random pattern and are under a normal probability curve. So, there are very strong chances that the process is under statistical control. However, an $X$-bar chart and $R$-bar chart cannot be drawn due to the low quantity of observational data. Now, again based upon observations of Table 1 , to understand whether the process is statistically controlled, ten samples of zinc alloy pieces were cast for all shell thickness values from $2 \mathrm{~mm}$ to $12 \mathrm{~mm}$. Based upon the observations in Table 5, a run-chart of the measured values of the outer diameter was developed (Figure 8).

Table 5. Benchmark dimensional value at different shell wall thicknesses from $2 \mathrm{~mm}$ to $12 \mathrm{~mm}$

\begin{tabular}{cccccc}
\hline S.NO & $\begin{array}{c}\text { Shell wall } \\
\text { thickness }(\mathbf{m m})\end{array}$ & Observation & Mean & $\begin{array}{c}\text { Above or } \\
\text { Below Mean }\end{array}$ & $\begin{array}{c}\text { Up or } \\
\text { Down }\end{array}$ \\
\hline 1 & 2 & 48.89 & 49.0184 & $\mathrm{~B}$ & \\
2 & 3 & 48.816 & 49.0184 & $\mathrm{~B}$ & $\mathrm{D}$ \\
3 & 4 & 48.453 & 49.0184 & $\mathrm{~B}$ & $\mathrm{D}$ \\
4 & 5 & 48.812 & 49.0184 & $\mathrm{~B}$ & $\mathrm{U}$ \\
5 & 6 & 49.529 & 49.0184 & $\mathrm{~B}$ & $\mathrm{U}$ \\
6 & 7 & 49.414 & 49.0184 & $\mathrm{~A}$ & $\mathrm{D}$ \\
7 & 8 & 49.265 & 49.0184 & $\mathrm{~A}$ & $\mathrm{U}$ \\
8 & 9 & 48.665 & 49.0184 & $\mathrm{~B}$ & $\mathrm{D}$ \\
9 & 10 & 48.954 & 49.0184 & $\mathrm{~B}$ & $\mathrm{U}$ \\
10 & 12 & 49.386 & 49.0184 & $\mathrm{~A}$ & $\mathrm{U}$ \\
MEAN & & 49.0184 & & $\mathrm{RUN}_{\mathrm{AB}=3}$ & $\mathrm{RUN}_{\mathrm{UD}=5}$ \\
\hline
\end{tabular}

$\mathrm{A}=$ above the mean, $\mathrm{B}=$ below the mean, $\mathrm{U}=$ up from previous reading, $\mathrm{D}=$ down from previous reading

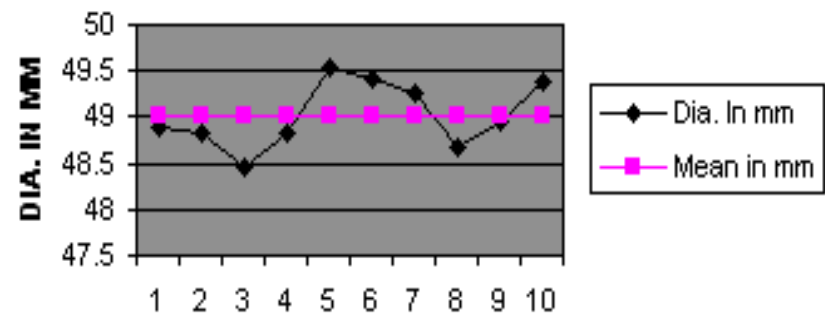

NO. OF OBSERVATION

Figure 8. Run-chart of measured values of benchmark (for shell thicknesses $2 \mathrm{~mm}$ to $12 \mathrm{~mm}$ ) 
Calculation for $Z$ (standard normal deviate) above and below (for shell thickness from $2 \mathrm{~mm}$ to $12 \mathrm{~mm}$ ):

$$
E(\text { run })_{A B}=\left(\frac{N}{2}+1\right)
$$

where $N$ is the number of observations and $E$ (run) $)_{\mathrm{AB}}$ is the expected number of runs above and below.

$$
\begin{gathered}
E(\text { run })_{A B}=\left(\frac{10}{2}+1\right)=6 \\
\sigma_{A B}=\sqrt{\left(\frac{N-1}{4}\right)}
\end{gathered}
$$

where $\sigma_{A B}$ is the standard deviation of above and below.

$$
\begin{gathered}
\sigma_{A B}=\sqrt{\left(\frac{10-1}{4}\right)}=1.5 \\
Z_{A B}=\left[R U N_{A B}-E(\text { run })_{A B}\right] / \sigma_{A B}
\end{gathered}
$$

where $R U N_{A B}$ is the actual number of runs obtained above and below.

$$
Z_{A B}=[3-6] / 1.5=-2
$$

$P=\operatorname{NORMSINV}(Z)$, when the value of $\mathrm{Z}$ is negative using Microsoft Excel software

$$
\begin{gathered}
P_{A B}=0.2275 \\
E(\text { run })_{U D}=\left(\frac{2 N-1}{3}\right)
\end{gathered}
$$

where $N$ is the number of observations and $E(\text { run })_{\mathrm{UD}}$ is the expected number of runs up and down.

$$
\begin{gathered}
E(\text { run })_{U D}=\left(\frac{2 \times 10-1}{3}\right)=6.33 \\
\sigma_{U D}=\sqrt{\left(16 N-\frac{29}{90}\right)}
\end{gathered}
$$

where $\sigma_{U D}$ is the standard deviation for up and down.

$$
\sigma_{U D}=\sqrt{\left(16 \times 10-\frac{29}{90}\right)}
$$




$$
\begin{gathered}
\sigma_{U D}=1.20646 \\
Z_{U D}=\left[R U N_{U D}-E(\text { run })_{U D}\right] / \sigma_{U D} \\
Z_{U D}=[5-6.33] / 1.20646 \\
Z_{U D}=-1.102398
\end{gathered}
$$

$P=\operatorname{NORMSINV}(\mathrm{Z})$, when the value of $\mathrm{Z}$ is negative in Microsoft Excel software

$$
P_{U D}=0.1351411
$$

Normally decision making is done with a certain margin of error ' $\alpha$ ' and taken as equal to 0.005 , indicating that there is a $5 \%$ chance of arriving at the wrong conclusion. Now, for decision making,

$$
\text { if } P_{A B}<\alpha \text { OR /and } P_{U D}<\alpha \text {, then a non-random pattern exists. }
$$

In the present case $P_{A B}$ and $P_{U D}$ are $>\alpha$, indicating the existence of a random pattern. So, there are very strong chances that the process is not under statistical control for all shell thicknesses from $2 \mathrm{~mm}$ to $12 \mathrm{~mm}$.

\section{CONCLUSIONS}

On the basis of experimental observations made on the zinc alloy castings obtained from different shell wall thicknesses, the following conclusions can be drawn:

1. It is feasible to reduce the shell thickness from the recommended value of 12 $\mathrm{mm}$ to $2 \mathrm{~mm}$. The tolerance grades of the castings produced from different thicknesses were consistent with the permissible range of tolerance grades (IT grades) as per standard UNI EN 20286-I (1995). The results are consistent with the observations made elsewhere.

2. Instead of a $12 \mathrm{~mm}$ shell thickness of mould in the $Z$ Cast process of casting for zinc alloys, one can select a $7 \mathrm{~mm}$ shell thickness, as observed from the better dimensional results and mechanical properties.

3. Strong possibilities are observed for the process under statistical control for the best set shell thickness $(7 \mathrm{~mm})$ in the case of zinc alloy, which is not observed for all shell wall thicknesses of mould cavities prepared with 3DP.

\section{ACKNOWLEDGEMENT}

The authors are thankful to AICTE, New Delhi for financial support under CAYT.

\section{REFERENCES}

Bassoli, E., Gatto, A., Iuliano, L. and Violante, M.G. 2006. 3D printing technique applied to rapid casting. Rapid Prototyping Journal, 13(3): 148-155.

Bernard, A., Delplace, C.J., Perry, N. and Gabriel, S. 2003. Integration of CAD and rapid manufacturing for sand casting optimization. Rapid Prototyping Journal, 5: 327-333. 
Devor, R.E., Chang, T. and Sutherland, J.W. 2005. Statistical quality design and control contemporary concepts and methods. (Second edition). New Jersey: Pearson Prentice Hall.

Dimitrov, D., Schreve, K. and de Beer, N. 2006. Advances in three dimensional printing - State of the art and future perspectives. Rapid Prototyping Journal, 12(3): 136147.

Dimitrov, D., Wijck, W., van de Beer, N. and Dietrich, J. 2007. Development, evaluation and selection of rapid tooling process chains for sand casting of functional prototypes. Journal of Engineering Manufacture, 221(B9): 14411450.

Kaplas, M. and Singh, R. 2008. Experimental investigations for reducing wall thickness in zinc shell casting using three dimensional printing. Proc. of IMechE Part C, Journal of Mechanical Engineering Sciences, 222(C12): 2427-2431.

Karapatis, N.P., Griethuysen, J.P.S. and Glardon, R. 1998. Direct rapid tooling: a review of current research. Prototyping Journal, 4(2): 77-89.

Radstok, E. 1999. Rapid tooling. Rapid Prototyping Journal, 5(4): 164-168.

Sachs, E.M., Haggerty, J.S., Cima, M.J. and Wiliams, A.P. 1994 Three dimensional printing techniques. United States Patent No. US 005340656.

Singh, J.P. and Singh, R. 2008. Investigations for reducing wall thickness in low brass rapid casting using three dimensional printing. International Conference on Advances in Mechanical Engineering (AME 2008), Department of Mechanical Engineering, Sardar Vallabhbhai National Institute of Technology, Surat, India, pp. 878-883.

Singh, J.P. and Singh, R. 2009a Comparison of rapid casting solutions for lead and alloys using three dimensional printing. Journal of Mechanical Engineering Sciences (Proc. of IMechE Part C), 223(C9): 2117-2123.

Singh, J.P. and Singh, R. 2009b Investigations for statistically controlled rapid casting solution of lead alloys using three dimensional printing. Journal of Mechanical Engineering Sciences (Proc. of IMechE Part C), 223(C9): 2125-2134.

Singh, R. 2008a. Comparison of wall thickness in shell casting of light alloys for generating cost effective prototype using 3DP. $2^{\text {nd }}$ International and $23^{\text {rd }}$ All India Manufacturing Technology, Design and Research Conference, IIT Madras, Chennai, pp. 1089-1093.

Singh, R. 2010. Three-dimensional printing for casting applications: A state of art review and future perspectives. Advanced Materials Research, 83-86:342-349.

Singh, R. and Verma, M. 2008. Investigations for reducing wall thickness of aluminium shell casting using three dimensional printing. Journal of Achievements in Materials and Manufacturing Engineering, 31(2): 565-569.

UNI EN 20286-1, 1995. ISO system of limits and fits. Bases of tolerances, deviations and fits.

Verma, M. 2008. Investigations for reducing wall thickness in aluminum shell casting using 3DP. M. Tech. Thesis, P.T.U. Jalandhar, India.

Wang, W., Conley, J.G. and Stoll, H.W. 1999. Rapid tooling for sand casting using laminated object manufacturing process. Rapid Prototyping Journal, 5(3): 134140. 